\title{
USO DO Vaccinium macrocarpon (CRANBERRY) NA PROFILAXIA DE INFECÇÕES DO TRATO URINÁRIO: REVISÃO INTEGRATIVA
}

Use of Vaccinium macrocarpon (Cranberry) in the prophylaxis of urinary tract

infections: integrative review

Uso de Vaccinium macrocarpon (Arádano) en la profilaxis de infecciones del tracto urinário:

revisión integrativa

Gabriela Cimadon ${ }^{1}$, Beatriz da Silva Rosa Bonadiman ${ }^{2} *$,

Graduanda em Farmácia, Universidade do Oeste de Santa Catarina, Xanxerê, Brasil ${ }^{1}$

Biomédica, Doutora em Bioquímica, docente na Universidade do Oeste de Santa Catarina, Xanxerê, Brasil ${ }^{2}$

*Correspondência: beadasilvarosa@gmail.com

Artigo recebido em 30/12/2020 aprovado em 14/10/2021 publicado em 22/10/2021.

\section{RESUMO}

Objetivo: Identificar através de uma revisão as propriedades antimicrobianas presentes no Vaccinium macrocarpon, o seu feito preventivo e como adjuvante no tratamento das ITUS. Método: Através de uma revisão bibliográfica nas bases de dados Scielo, PubMed e Lilacs, onde foram encontrados mais de 2000 artigos ao inserir as palavras cranberry, trato urinário, fitoterapia or terapia de ervas or terapia herbária, no campo de busca. A partir disso foram selecionados os artigos entre 2007 até 2021 que apresentavam informações referentes aos compostos presentes na fruta e de que maneira exerciam seu efeito terapêutico, de modo a diminuir a incidência de infecção urinária através da inibição do crescimento bacteriano. Resultados: A fruta pode atuar inativando a Escherichia coli uma das maiores causadoras dessas infecções, por meio da inativação de seus genes e através da redução das funções, impedindo a sua multiplicação e assim culminando na morte das cepas bacterianas. Conclusão: Foi possível observar que os seus princípios ativos antocianidinas e as proantocianidinas impedem a adesão das fímbrias bacterianas no trato urinário, e ainda reduzem os fatores de virulência bacteriana assim é possível inativar as funções vitais da bactéria levando a sua morte. Desse modo foi possível observar que o Vaccinium macrocarpon pode ser utilizado como tratamento e como uma medida profilática devido a sua capacidade de reduzir a incidência de infecção urinária.

Palavras-chave: Cranberry, infecção urinária, fitoterapia.

\section{ABSTRACT}

Objective: To identify, through a review, the antimicrobial properties present in Vaccinium macrocarpon, its preventive effect and as an adjuvant in the treatment of UTIs. Method: Through a literature review in Scielo, PubMed and Lilacs databases, where more than 2000 articles were found by inserting the words cranberry, urinary tract, phytotherapy or herbal therapy or herbal therapy, in the search field. From this, articles were selected between 2007 and 2021 that presented information regarding the compounds present in the fruit and how they exerted their therapeutic effect, in order to reduce the incidence of urinary tract infections through the inhibition of bacterial growth. Results: The fruit can act by inactivating Escherichia coli, one of the main causes of these infections, through the inactivation of its genes and by reducing its functions, preventing its multiplication and thus culminating in the death of the bacterial strains. Conclusion: It was possible to observe that its active principles anthocyanidins and proanthocyanidins prevent the adhesion of bacterial fimbriae in the urinary tract, and also reduce bacterial virulence factors so it is possible to inactivate the vital functions of the bacteria leading to its death. Thus, it was possible to 
observe that Vaccinium macrocarpon can be used as a treatment and as a prophylactic measure due to its ability to reduce the incidence of urinary tract infections.

Keywords: Cranberry, urinary infection, phytotherapy.

\section{RESUMEN}

Objetivo: Identificar, a través de una revisión, las propiedades antimicrobianas presentes en Vaccinium macrocarpon, su efecto preventivo y como coadyuvante en el tratamiento de las ITU. Método: A través de una revisión de la literatura en las bases de datos Scielo, PubMed y Lilacs, donde se encontraron más de 2000 artículos insertando las palabras arándano, tracto urinario, fitoterapia o fitoterapia o fitoterapia, en el campo de búsqueda. A partir de esto, se seleccionaron artículos entre 2007 y 2021 que presentaban información sobre los compuestos presentes en la fruta y cómo ejercían su efecto terapéutico, con el fin de reducir la incidencia de infecciones del tracto urinario mediante la inhibición del crecimiento bacteriano. Resultados: El fruto puede actuar inactivando Escherichia coli, una de las principales causas de estas infecciones, inactivando sus genes y reduciendo sus funciones, impidiendo su multiplicación y culminando así con la muerte de las cepas bacterianas. Conclusión: Se pudo observar que sus principios activos antocianidinas y proantocianidinas previenen la adhesión de fimbrias bacterianas en el tracto urinario, y también reducen los factores de virulencia bacteriana por lo que es posible inactivar las funciones vitales de las bacterias que conducen a su muerte. Así, se pudo observar que Vaccinium macrocarpon puede utilizarse como tratamiento y como medida profiláctica debido a su capacidad para reducir la incidencia de infecciones del tracto urinario.

Descriptores: Arándano. infección urinário, fitoterapia.

\section{INTRODUÇÃO}

O Cranberry é conhecido cientificamente como Vaccinium macrocarpon, faz parte da família da Ericaceae se desenvolve em ambientes úmidos, como florestas e pântanos nos países norte-americanos (SAONA et al. 2011). Ele é amplamente utilizado pelos povos Nativos Americanos e pelos Europeus como um alimento e também na medicina tradicional por benefícios à saúde como: cardioprotetor, anticarcinogênico e prevenção de úlceras estomacais (BISWAS et al. 2012; FRANÇA et al 2014).

Segundo a pesquisa de Salo et al. (2012) afirmam que a fruta é composta por $88 \%$ de água, ácido orgânico, frutos, vitamina $\mathrm{C}$, flavonóides, catequinas e antocianidinas. Ela pode ser encontrada na forma de frutas secas, extratos e sucos, que usualmente contêm apenas 10 à 25\% de Cranberry concentrado. Além disso, Salo et al (2012) revelam que as antocianidinas e as proantocianidina presentes no Cranberry, são taninos com uma função de defesa natural contra microrganismos, como os que são responsáveis por infeções do trato urinário (ITU).
De acordo com Filho et al. (2010), a ITU representa um local frequente de infecção, podendo ser sintomática ou assintomática. Também pode ser classificada quanto à sua localização, quanto atinge o trato urinário baixo, bexiga, é denominada cistite e quanto acomete o trato urinário alto, rins, é chamada de pielonefrite.

É uma patologia que tem prevalência em todas as populações, porém atinge principalmente o sexo feminino. Aproximadamente 50\% a 70\% das mulheres apresentaram pelo menos um episódio de ITU em suas vidas, sendo que $20 \%$ a $30 \%$ destas apresentam episódios recorrentes (SIMÕES; SOUZA, 2018).

As ITU são comuns em todo o mundo, e estima-se que 150 milhões de pessoas sejam afetadas por ano, e 95\% dos casos são causadas por bactérias Gram-negativas, sendo a Escherichia coli a mais frequente, conforme dados descritos por Shanmugapriya e Ushadevi (2014).

No Brasil, as ITU, são responsáveis por $80 \mathrm{em}$ cada 1.000 consultas clínicas, estatística que torna essa 
infeção a mais comum da população brasileira (MULLER et al. 2008)

No estado de Santa Catarina na cidade de Florianópolis, um levantamento da demanda nas unidades básicas de saúde apontou essa afecção como o $14^{\circ}$ motivo de consulta no município, ficando atrás, entre as causas infecciosas, apenas da infecção aguda do aparelho respiratório superior e da gastroenterite (GUSSO, 2009).

Oliveira e Santos (2018), abordaram um estudo sobre a prevalência das infecções urinárias em pacientes mato-grossenses através das análises dos prontuários dos exames realizados em 2016 e dos 118 casos positivos para infecção bacteriana, a maioria era de mulheres com idade de 19 a 40 anos e isso revela a importância de implementar políticas públicas, voltadas para a prevenção desta doença nas mulheres.

Quanto de trata de ITUS o tratamento de primeira linha é antibioticoterapia, que é eficaz, no entanto, essa estratégia pode implicar no aparecimento de cepas de microrganismos resistentes (GUPTA et al. 2011).

Esse padrão de resistência varia de acordo com a região do estudo. $\mathrm{Na}$ América Latina, foram encontradas altas porcentagens de cepas de E. coli resistentes a fluoroquinolonas (17,5-18,9\%), ampicilina $(61,4 \%)$ e amoxicilina, ácido clavulânico $(18,6 \%)$, ceftriaxona $(20,5 \%)$, gentamicina $(25,0 \%)$ e trimetropina/ sulfametoxazol (45\%) (VENTURA, 2016).

Sendo assim, considerando o aumento significativo dos casos de ITUs e somado a alta incidência de cepas microbianas resistentes aos antibióticos, torna-se necessário buscar tratamentos alternativos, e Jepson et al. (2012) relatam que o Vaccinium macrocarpon pode reduzir dentro de um ano o número ITUs, principalmente em mulheres que possuem infecções recorrentes.

Diante disso, a utilização de plantas medicinais no tratamento da doença, é recomendações da Organização Mundial da Saúde (OMS), no Brasil é normatizando pelo Sistema Único de Saúde por meio de Políticas Públicas de Saúde, como o Programa Nacional de Plantas Medicinais e Fitoterápicos (MACEDO, 2016).

Sendo assim, discute-se à necessidade de buscar tratamentos complementares para essa infecção, assim, o objetivo desse estudo consiste em identificar através de uma revisão integrativa as propriedades antimicrobianas presentes no Vaccinium macrocarpon, o seu feito preventivo e como adjuvante no tratamento das ITUS.

\section{MATERIAIS E MÉTODOS}

Trata-se de uma revisão integrativa de literatura. $\mathrm{O}$ delineamento do estudo tratou-se de uma abordagem qualitativa, de objetivo descritivo e explicativo.

A pesquisa foi realizada através de uma revisão bibliográfica em literaturas, nas bases de dados, Lilacs, Scielo e PubMed, com o objetivo de responder a seguinte questão norteadora deste estudo, "As propriedades presentes no Cranberry, previnem infecções do trato urinário?" Para realizar a busca, inseriu-se no descritor "Cranberry", "Trato Urinário", "Fitoterapia or Terapia de Ervas or Terapia Herbária". Os idiomas para inclusão foram o português e inglês e os anos de publicações foram entre 2007 e 2021.

Foram excluídos da pesquisa, os artigos que foram publicados antes de 2007, os trabalhos repetidos e os que não foram possíveis de obter a versão completa do artigo, e além disso não foram mantidos os que não atendiam a temática deste trabalho que é a abordagem do cranberry mediante a infecção urinária. 
Figura 1. Fluxograma sobre a metodologia utilizada na seleção dos artigos.

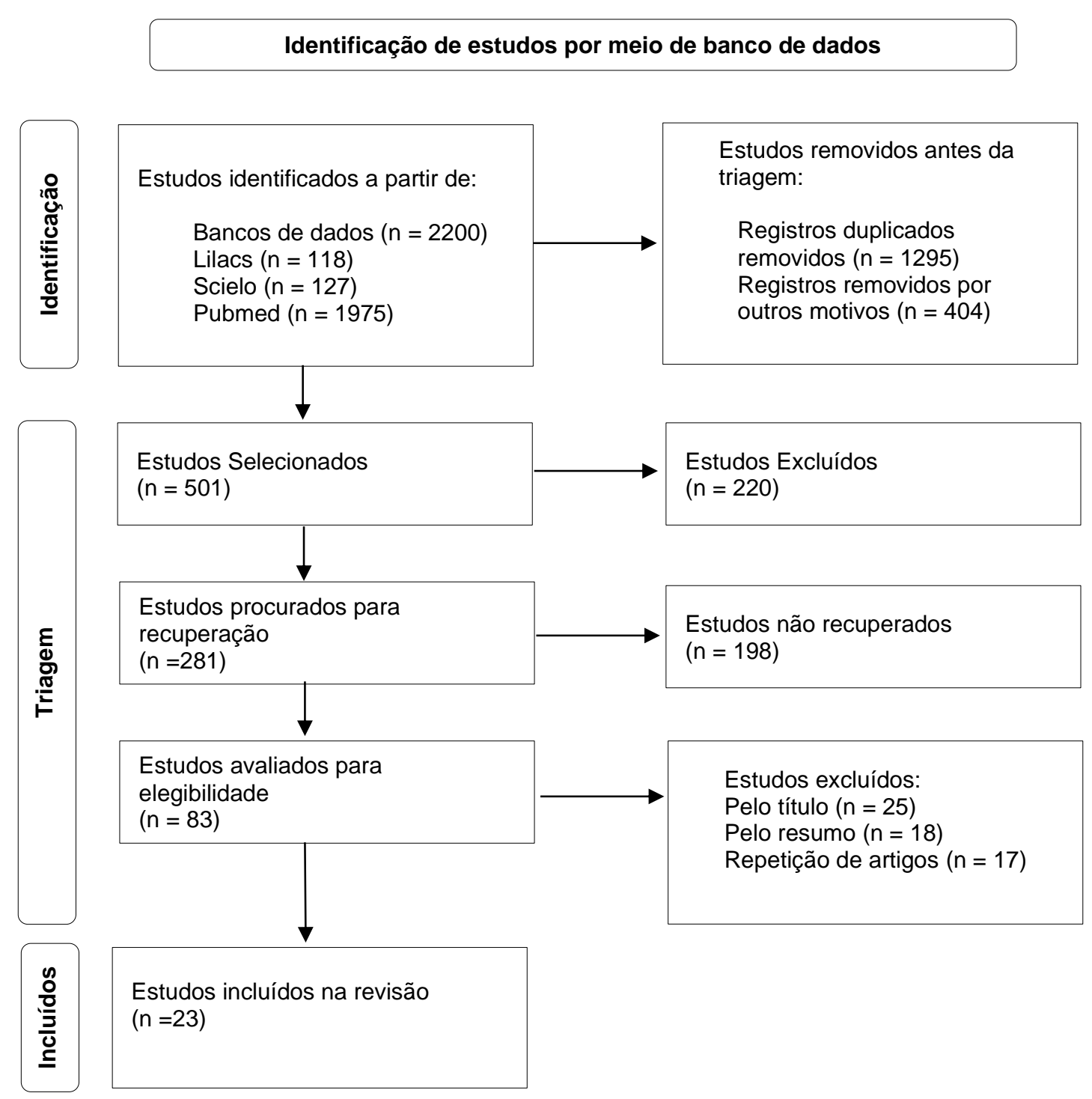

\section{RESULTADOS}

Foram encontrados 2200 artigos, e destes

foram excluídos 2182, pelo fato de não atenderem os critérios de inclusão, ou seja, o título e o resumo destes artigos não eram específicos sobre as características do cranberry e sobre a sua ação na infecção urinária, e o outro motivo de exclusão foi devido aos estudos encontrarem repetidos nas bases de dados.

Diante disso, foram mantidos 23 artigos que foram lidos na íntegra e foram utilizados como

referência para esta pesquisa pelo fato de eles atenderem os critérios de inclusão e responderam pergunta norteadora para a construção do trabalho.

De acordo com os 23 artigos escolhidos para essa revisão de literatura, 6 destes artigos falam sobre as características botânicas e farmacológicas do Vaccinium macrocarpon, 5 abordam as características dos seus princípios ativos, as proantocianidinas e antocianidinas e o seu afeito antibacteriano. E 5 dentre os artigos selecionados trouxeram dados quantitativos 
sobre os pacientes e seus relatos de caso referente a infecção urinária.

No Quadro 1, os artigos foram caracterizados, como uma maneira de identificação de cada um dos estudos descritos com os experimentos realizados em cada um deles e os respectivos resultados obtidos.

\section{DISCUSSÃO}

Nesse estudo foi identificado que diferentes preparações do cranberry, tem ação sobre a Escherichia coli principal microrganismo causador da ITU.

Os derivados da fruta do Cranberry foram identificados como compostos que interferem na adesão bacteriana em diferentes tecidos, a propriedade antiaderente deste alimento está atribuída em grande parte pela presença dos compostos específicos proantocianidinas, na qual, são taninos condensados que consistem em monômeros de catequina e epicatequina (FRANÇA et al. 2014).

Pina et al. (2011), afirmam que o fruto tem um mecanismo de ação baseado no poder que as proantocianidinas e a frutose, presentes nele, têm de inibirem a aderência das fímbrias das bactérias uropatogênicas às células do tecido epitelial. Com isso, há a inibição de crescimento bacteriano nesse local.

A seguir está descrito o Quadro 1, com o detalhamento dos experimentos realizados e os seus resultados obtidos.

Quadro 1. Descrição dos experimentos realizados e seus resultados obtidos

\begin{tabular}{|c|c|c|c|c|}
\hline Ano & Autor & Título & Experimento & Resultado \\
\hline 2016 & Ventura & $\begin{array}{l}\text { Infecção do trato urinário por } \\
\text { Escherichia coli resistente a } \\
\text { antibióticos tratados com } \\
\text { Vaccinum macrocarpon: relato } \\
\text { de caso. }\end{array}$ & $\begin{array}{l}\text { Paciente com infecção urinária } \\
\text { recorrente e resistente ao } \\
\text { Ciprofloxacino foi submetida ao } \\
\text { tratamento com Cranberry. } \\
\text { Consumiu } 5 \mathrm{~g} \text { do fruto, quantidade } \\
\text { equivalente a } 18 \mathrm{mg} \text { de } \\
\text { proantocianinas, dissolvido em } \\
250 \mathrm{~mL} \text { de água, administrado } \\
\text { duas vezes ao dia durante } 20 \text { dias }\end{array}$ & $\begin{array}{l}\text { Após } 6 \text { dias de } \\
\text { tratamento, ela estava } \\
\text { assintomática e com a } \\
\text { urocultura negativa. } \\
\text { Assim a paciente } \\
\text { permaneceu no decorrer } \\
\text { das semanas, concluindo } \\
\text { que a terapia foi eficaz no } \\
\text { tratamento. }\end{array}$ \\
\hline 2018 & $\begin{array}{l}\text { Ranfaig et } \\
\text { al. }\end{array}$ & $\begin{array}{l}\text { A própolis potencializa o efeito } \\
\text { do cranberry (Vaccinium } \\
\text { macrocarpon) contra a } \\
\text { virulência de Escherichia coli } \\
\text { uropatogênica. }\end{array}$ & $\begin{array}{l}\text { Análise dos níveis de expressão do } \\
\text { genoma bacteriano de } E \text {. coli } \\
\text { medidos na presença de cranberry } \\
\text { contendo } 190 \mu \mathrm{g} / \mathrm{mL} \text { de } \\
\text { proantocianidinas e com } 102,4 \mu \mathrm{g} \\
\text { / mL do extrato de própolis. Foram } \\
\text { avaliados cada composto } \\
\text { separadamente e em um segundo } \\
\text { momento foram analisados juntos. }\end{array}$ & $\begin{array}{l}\text { A administração da } \\
\text { própolis junto com o } \\
\text { cranberry demonstrou um } \\
\text { melhor efeito } \\
\text { antibacteriano mediante a } \\
\text { E. coli devido ao aumento } \\
\text { da proteção contra a } \\
\text { adesão, motilidade, } \\
\text { biofilme, multiplicação } \\
\text { bacteriana e a sua } \\
\text { virulência no trato } \\
\text { urinário. }\end{array}$ \\
\hline 2019 & $\begin{array}{l}\text { Saramarasi } \\
\text { nghe et al. }\end{array}$ & 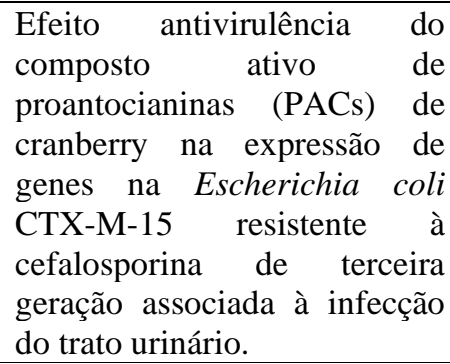 & $\begin{array}{l}\text { Estudo realizado com um isolado } \\
\text { de Escherichia coli CTXM-15 } \\
\text { submetido à análise por qRT-PCR, } \\
\text { do comportamento dos fatores de } \\
\text { virulência após o tratamento com o } \\
\text { Cysticlean®. }\end{array}$ & $\begin{array}{l}\text { O Cysticlean }{ }^{\circledR} \text { reduziu } \\
\text { significativamente a } \\
\text { expressão de uma grande } \\
\text { variedade de genes } \\
\text { responsáveis pela aptidão } \\
\text { e virulência. }\end{array}$ \\
\hline
\end{tabular}


De acordo com as investigações descritas, o cranberry demonstrou eficiência no combate a infecções por Escherichia coli, pelo fato da fruta reduzir as funções vitais da bactéria e com isso ocasionando a sua morte.

Ventura (2016), trouxe o relato de uma mulher de 42 anos, que sofre desde os 20 anos com infecção urinária recorrente, e que apresentava disúria, micção frequente e dor supra púbica, a intensidade dos sintomas foram aumentando e ela automedicou-se com Ciprofloxacino via oral, durante 3 dias, no entanto, ao realizar a urocultura descobriu que estava com Escherichia coli e que era resistente ao antibiótico que fazia uso. Diante disso, foi sugerido a paciente realizar uma terapia alternativa e ela foi informada dos riscos e benefícios e decidiu testar o tratamento com extrato de Cranberry.

O tratamento descrito por Ventura (2016) consistiu no consumo de $5 \mathrm{~g}$ do fruto, quantidade equivalente a $18 \mathrm{mg}$ de proantocianinas, dissolvido em $250 \mathrm{~mL}$ de água, administrado duas vezes ao dia durante 20 dias, e durante esse período a paciente recebeu acompanhamento médico. Após 6 dias da conclusão do tratamento, ela encontrava-se assintomática, seu exame de urina estava normal, e a urocultura com antibiograma encontrava-se negativo. Após 13 semanas, a mulher continuava assintomática e nas culturas de urina que foram realizadas nesse período permaneceram negativas quanto ao crescimento bacteriano.

Como alternativa no tratamento de ITU provocada por E. coli Ranfaig et al. (2018), apresentaram um estudo que avaliava os níveis de expressão do genoma dessa bactéria e foram medidos na presença dos produtos de cranberry e própolis separadamente e depois comparados com os do isolado não tratado. Observaram que o cranberry juntamente com a própolis atuaram favorecendo a proteção contra a adesão, motilidade, biofilme, multiplicação bacteriana e a sua virulência no trato urinário. Além disso, os autores afirmaram que a administração dos dois compostos juntos foi capaz de fazer à própolis intensificar a ação do cranberry e com isso obteve-se o efeito terapêutico desejado.

Há outra pesquisa que foi realizada por Simões e Souza (2018), onde utilizaram a mesma bactéria que foi descrita anteriormente, e foi submetida à avaliação in vitro com suco do Vaccinum macrocarpon para testar a sua atividade antibacteriana contra as suas cepas.

Simões e Souza (2018) inocularam as cepas em placas de Ágar I, II e em microplaca onde colocaram pequenas quantidades do suco cerca de 0,1 $\mathrm{mL}$ em cada uma das amostras e observaram que não houve a inibição do crescimento bacteriano, pelo fato e não haver a formação de halo de inibição e devido a e turvação nos sucos na diluição da microplaca, e a partir disso indicaram que houve o desenvolvimento da bactéria.

Saramarasinghe et al. (2019), apresentaram um estudo realizado com um isolado de Escherichia coli CTXM-15, escolhido pelo fato de ter sido considerado de rápida disseminação e resistente a alguns grupos de antibióticos. Foi submetido à análise por qRT-PCR (reação quantitativa em cadeia da transcriptase reversa - polimerase em cadeia), do comportamento dos fatores de virulência após o tratamento com o Cysticlean ${ }^{\circledR}$, produto a base de Cranberry que contém cerca de $240 \mathrm{mg}$ de proantocianinas.

Os dez genes selecionados desempenham papéis significativos na função normal da célula, como aquisição de ferro, produção de toxinas e sobrevivência ao estresse na E. coli resistente à cefalosporina de terceira geração, e sua expressão genética relativa foi determinada após a exposição ao produto Cysticlean ${ }^{\circledR}$ usando qRT-PCR. Os resultados $\begin{array}{lllll}\text { mostraram que } & \text { o } & \text { Cysticlean }{ }^{\circledR} & \text { reduz }\end{array}$ 
significativamente a expressão de uma 10 grande variedade de genes responsáveis pela aptidão e virulência. (SARAMARASINGHE et al. 2019)

Isso pode ser observado através de dois mecanismos complementares que foram sugeridos para explicar a capacidade do cranberry americano em reduzir infecções do trato urinário. $\mathrm{O}$ primeiro mecanismo foi creditado à sua atividade biocida, possibilitada pela produção de vários elementos que podem danificar bactérias. O segundo mecanismo é atribuído à sua atividade antivirulência, através da regulação negativa e interferência com múltiplos fatores de virulência associados à tolerância ao estresse e à sobrevivência no trato urinário. $\mathrm{O}$ último poderia finalmente resultar no enfraquecimento das habilidades de sobrevivência bacteriana e sua capacidade de causar infecção (OTHMAN, 2016)

Outro estudo em andamento na Universidade da Califórnia apresentou dados preliminares que sugerem que o suco de cranberry tem alguma atividade antibacteriana, através de uma preparação cinco vezes mais concentrada que o suco comercialmente disponível, mostrando que o cranberry pode ter, sim, ação inibitória além da profilática já demonstrada (HISANO et al. 2012).

O estudo de Hisano et al. (2012) pode ser uma justificativa para fato de o estudo apresentado por Simões e Souza (2018) não ter obtido um resultado satisfatório de inibição do crescimento microbiano. Isso pode ter ocorrido devido a concentração da fruta no suco ser uma quantidade menor que a necessária para conseguir agir na bactéria e inativa-la. Isso torna necessário o uso de maiores doses para que os componentes responsáveis pelo efeito antibacteriano consigam exercer seu efeito farmacológico.

De acordo com a ANVISA (2021) que apresenta o Formulário de Fitoterápicos na Farmacopeia Brasileira, aborda que a dose recomendada do extrato seco de cranberry presente em uma cápsula deve ser de 400 a 500mg para que o paciente obtenha o efeito terapêutico e de prevenção mediante as infecções urinárias.

Valentova et al. (2007), relataram o seu estudo realizado com 65 mulheres jovens e saudáveis, que fizeram o consumo do suco do cranberry desidratado por 8 semanas, e observaram que uma dose 1200mg foi capaz de diminuir significativamente os níveis séricos de produtos de proteína de oxidação avançada, é um efeito protetor específico contra o dano oxidativo das proteínas. $\mathrm{E}$ as amostras de urina tiveram um efeito inibitório na adesão de cepas de Escherichia coli uropatogênica e com isso observaram sua ação na prevenção de infecções do trato urinário e na prevenção do estresse oxidativo.

Um estudo realizado por Lavigne et al. (2008) avaliou oito voluntários saudáveis que foram submetidos ao consumo de cápsulas do Vaccinium macrocarpon e os resultados obtidos pelos autores confirmou a existência de um efeito dose-dependente na adesão in vitro de $E$. coli às células epiteliais da bexiga e demonstraram que a administração de três cápsulas, totalizando $108 \mathrm{mg}$ de extrato de cranberry pode representar uma abordagem alternativa interessante para a prevenção de ITU, seguida de um regime de uma cápsula contendo $36 \mathrm{mg}$ por dia para favorecer a profilaxia das infecções urinárias.

Com base nessa concentração descrita por Lavigne et al. (2008), Souza e seus colaboradores (2016), testaram um extrato contendo $64 \mathrm{mg}$ de proantocianidinas, mediante a algumas bactérias patogênicas, e observaram que o efeito antimicrobiano foi eficaz e levou a inibição do Staphylococcus aureus, Klebsiella pneumoniae, Escherichia coli, Serratia marscecens e Enterococcus faecalis que são causadores de infecção do trato urinário.

Os princípios ativos encontrados na literatura, foram as proantocianidinas e antocianidinas que possuem a função de impedir que as fímbrias presentes 
na parede das bactérias consigam se aderir a parede do trato urinário e por meio disso foi possível obter o efeito antibacteriano. Além disso o Vaccinium macrocarpon demostrou ter ação nos fatores de virulência da bactéria, conseguiu enfraquecer a célula bacteriana, interferindo em fatores responsáveis pela sua sobrevivência dentro do organismo humano e desse modo levou a morte celular bacteriana.

Comparando os estudos, pode-se afirmar que o cranberry tem eficácia na infecção urinária ocasionada por E. coli por ser capaz de reduzir a sua atividade bacteriana de diferentes maneiras. Além disso, pode ser considerada como uma alternativa na prevenção e no tratamento dos episódios de ITU. Diante disso é fundamental que novos estudos sejam realizados para especificar qual é a quantidade da fruta que precisa ser consumida para que seja possível obter o efeito terapêutico desejado.

Diante disso, observa-se que o Vaccinium macrocarpon foi capaz de impedir a proliferação bacteriana de diversas maneiras e que é uma medida profilática para a redução na incidência de infecções urinárias.

\section{CONCLUSÃO}

As informações permitem concluir que o uso do Vaccinum macrocarpon é uma terapia eficaz nos casos de infecção urinária, e é uma profilaxia para casos de infecção recorrente devido a ação das proantocianidinas e antocianidinas que são os princípios ativos presentes na fruta, que impedem que as fímbrias das bactérias consigam se fixar na parede do trato urinário e assim não conseguem se aderir e levar a infecção.

O outro fator deve-se pela ação anti-virulência que vai atuar provocando o enfraquecimento da bactéria até levar a sua completa inativação.

Diante disso, por meio deste estudo foi possível observar que o cranberry tem ação antibacteriana mediante as infecções do trato urinário e que ele pode ser usado como tratamento e como uma prevenção para os pacientes que possuem infecção recorrente pois ele demonstrou eficácia nos estudos apresentados e com isso proporciona uma melhor qualidade de vida.

Todos os autores declararam não haver qualquer potencial conflito de interesses referente a este artigo.

\section{REFERÊNCIAS}

AGÊNCIA NACIONAL DE VIGILÂNCIA SANITÁRIA. Formulário de Fitoterápicos da Farmacopeia Brasileira. Ed. 2. p. 201-202. Brasília. 2021. Acesso em: 03. Fev. 2021. Disponível em: https://www.gov.br/anvisa/ptbr/assuntos/farmacopeia/formulariofitoterapico/arquivos/2021-fffb2-final-c-capa2.pdf

BISWAS, Nirupam. et al. Identificação de compostos fenólicos em cranberries processados pelo método HPLC . Nutr. Food Sci., v.3, n.1, p.18, 2012. Acesso em: 24.fev.2020. Disponível em: https://www.redalyc.org/pdf/260/26037787007.pdf

FILHO, Jarbas Roriz et al. Infecção do Trato Urinário. Revistas USP, v. 43, n. 2, p. 118-125. Ribeirão Preto. 2010. Acesso em: 24. Fev. 2020. Disponível em: https://www.revistas.usp.br/rmrp/article/view/166/16 7

FRANÇA, Ana Carolina Yoshida da Rocha et al. O Consumo do Cranberry no Tratamento de Doenças Inflamatórias. Ensaios e Ciência: Ciências Biológicas, Agrárias e da Saúde. Campo Grande: Ed. Universidade Anhanguera, vol. 18, núm. 1. p. 47-53. 2014. Acesso em: 24.fev.2020. Disponível em: https://www.redalyc.org/pdf/260/26037787007.pdf

GUPTA, Kalpana et al. Diretrizes de prática clínica internacional para o tratamento de cistite aguda não complicada e pielonefrite em mulheres: uma atualização de 2010 pela Sociedade Americana de Doenças Infecciosas e pela Sociedade Europeia de Microbiologia e Doenças Infecciosas. Revista Doenças Infecciosas Clínicas, Oxford, v. 52, p. 103120, 2011. Acesso em: 25. Fev. 2020. Disponível em: https://academic.oup.com/cid/article/52/5/e103/38828 5

GUSSO, Gustavo Diniz Ferreira. Diagnóstico de demanda em Florianópolis utilizando a Classificação Internacional de Atenção Primária: $2^{\mathrm{a}}$ edição (CIAP2) [tese]. São Paulo. Universidade de São Paulo; 2009. 
168 p. [Citado 10 Set 2014]. Acesso em: 5. Ago. 2020. Disponível

em:

http://www.teses.usp.br/teses/disponiveis/5/5159/tde08032010-164025/pt-br.php

HISANO, Marcelo et al. Cranberries e prevenção de infecções do trato urinário inferior. Clínicas. São Paulo. 2012; 67(6):661-8 Acesso em: 21. Mar. 2020. Disponível

em: http://docs.bvsalud.org/biblioref/2019/11/1024973/rb ac-vol-51-2-2019-ref-745.pdf

JEPSON, Ruth et al. Airelas para prevenir infecções do trato urinário. Cochrane Database Syst Rev. 2012. Acesso em: 24.fev.2020. Disponível em: http://www.scielo.br/scielo.php?script=sci_arttext\&pi $\mathrm{d}=$ S1516-31802013000500363

LAVIGNE, Jean Philippe et al. Evidência in vitro e in vivo de diminuição dependente da dose da virulência de Escherichia coli uropatogênica após o consumo de cápsulas comerciais de Vaccinium macrocarpon (cranberry). Paris. 2008. Acesso em: 28. Jan. 2021. Disponível em: https://www.ncbi.nlm.nih.gov/pmc/articles/PMC4749 $672 /$

MACEDO, Jussara Alice Beleza. Plantas Medicinais e Fitoterápicos na Atenção Primária a Saúde: Contribuição Para Profissionais Prescritores. Rio de Janeiro. 2016. Acesso em: 24.fev.2020. Disponível em:

https://www.arca.fiocruz.br/bitstream/icict/17719/2/1 2.pdf

MULLER, Erildo et al. Prevalência de microrganismos em infecções do trato urinário de pacientes atendidos no laboratório de análises clínicas da Universidade Paranaense - Umuarama - PR. Rev bras anal clin. 2008; 40(1):35-7. Acesso em: 13. Ago. $2020 . \quad$ Disponível em: https://pesquisa.bvsalud.org/portal/resource/pt/lil510673

OLIVEIRA, Sérgio Marcelino. SANTOS, Ludimylla Lins Gondim dos. Infecção do trato urinário: estudo epidemiológico em prontuários laboratoriais. Journal Health NPEPS. 2018; 3(1):198-210. Mato Grosso. 2018 Acesso em: 13. Ago. 2020. Disponível em: file://C:/Users/Windows/Downloads/2843-9988-2PB\%20(2).pdf

OTHMAN Mohammad. O cranberry é eficaz na prevenção de infecções recorrentes do trato urinário em mulheres. IOSR J Farmácia. 2016: 7-15. Acesso em: 21. Mar. 2020. Disponível em: https://www.ncbi.nlm.nih.gov/pmc/articles/PMC6865 039/
PINA, Alexandra et al. Arando na profilaxia das infecções urinárias recorrentes: revisão baseada na evidência. Revista Portuguesa de Clínica Geral, Matosinhos, v.27, p.452457, 2011. Acesso em: 24. Fev.2020. Disponível em: http://www.rbac.org.br/artigos/avaliacao-in-vitro-daatividade-antibacteriana-de-sucosde-cranberryvaccinium-macrocarpon-sobre-cepas-de-escherichiacoli-responsaveispor-infeccao-urinaria/

RANFAIG, Jéremy et al. A própolis potencializa o efeito do cranberry ( Vaccinium macrocarpon ) contra a virulência de Escherichia coli uropatogênica. 2018. Acesso em: 21. Mar. 2020. Disponível em: https://www.ncbi.nlm.nih.gov/pmc/articles/PMC6048 $107 /$

SALO, Jarmo. et al. Suco de cranberry para a prevenção de recorrências de infecções do trato urinário em crianças: um estudo randomizado controlado por placebo. 2011. Acesso em: 24.fev.2020. Disponível em: https://www.redalyc.org/pdf/260/26037787007.pdf

SAMARASINGHE, Shivanthi. et al. O efeito antivirulência do composto ativo de proantocianinas (PACs) de cranberry na expressão de genes em Escherichia coli CTX-M-15 resistente a cefalosporina de terceira geração associada à infecção do trato urinário. 2016. Acesso em: 21. Mar. 2020. Disponível em:

https://www.ncbi.nlm.nih.gov/pmc/articles/PMC6865 039/

SAONA, Cesar Rodrigez. et al. Traçando a história de características de plantas sob domesticação em cranberries: consequências potenciais sobre as defesas antiherbívoros. Diário da Botânica Experimental, v.62, n.8, p.2633- 2644, 2010. Acesso em: 24.fev.2020. Disponível em: https://www.redalyc.org/pdf/260/26037787007.pdf

SHANMUGAPRIYA, R. USHADEVI T. Atividades antibacteriana e antioxidante in vitro de extratos de sementes de Apium graveolens L. Int J Drug Dev Res. 2014;6(3):165-70. Acesso em: 13. Ago. 2020. Disponível em: https://www.ijddr.in/drugdevelopment/in-vitro-antibacterial-and-antioxidantactivities-of-apium-graveolens-lseed-extracts.pdf

SIMÕES, Ludmila Pini. SOUZA, Louremi Bianchi Gualda de. Avaliação in vitro da atividade antibacteriana de sucos de cranberry (Vaccinium macrocarpon) sobre cepas de Escherichia coli responsáveis por infecção urinária. Maringá PR. 2018. Acesso em: 24.fev.2020. Disponível em: http://www.rbac.org.br/artigos/avaliacao-in-vitrodaatividade-antibacteriana-de-sucos-de-cranberry- 
vaccinium-macrocarpon-sobre-cepasde-escherichiacoli-responsaveis-por-infeccao-urinaria/

SOUZA, Carla Franco Porto Belmont et al. Efeito antimicrobiano do extrato de cranberry sobre microorganismos causadores de infecção urinária. Cadernos UNIFOA. Ed. 31. p. 113-122. Volta Redonda. 2016. Acesso em: 03. Fev. 2021. Disponível em: file:///C:/Users/Windows/Downloads/384-2478-1PB.pdf

VALENTOVA, Katerina et al. Biossegurança, status antioxidante e metabólitos na urina após o consumo de suco de cranberry desidratado em mulheres saudáveis: um estudo piloto duplo-cego controlado por placebo. Jornal de Química Agrícola e Alimentar. Ed. 55 Vol. 8. p. 3217-24. República Tcheca. 2007. Acesso em: 28. Mai. 2021. Disponível em: http://www.medchem.upol.cz/PUBLIKACE/jf063601 4.pdf

VENTURA, José Aranda. Infecção do trato urinário por Escherichia coli resistente a antibióticos tratados com Vaccinum macrocarpon: relato de caso. 2016. Acesso em: 21. Mar. 2020. Disponível em: http://rpmi.pe/ojs/index.php/RPMI/article/view/19/14 